\title{
Intrarenal artery pseudoaneurysm after blunt abdominal trauma: a case report of successful superselective angioembolization
}

This article was published in the following Dove Press journal:

Research and Reports in Urology

2 April 2014

Number of times this article has been viewed

\author{
T Antunes-Lopes ${ }^{1,2}$ \\ R Pinto ${ }^{1,2}$ \\ P Morgado 3 \\ P Madaleno ${ }^{3}$ \\ J Silva ${ }^{1,2}$ \\ C Silva ${ }^{1,2}$ \\ F Cruz ${ }^{1,2}$
}

'Department of Urology, Hospital de São João, ${ }^{2}$ Faculty of Medicine, University of Porto, ${ }^{3}$ Department of Radiology, Hospital de São João, Porto, Portugal
Correspondence: T Antunes-Lopes Department of Urology, Hospital de S. João, Alameda Prof Hernâni Monteiro, 4200-31 9 Porto, Portugal

Tel +35 I 913742073

Fax +35I 225095618

Email tiagoantuneslopes@gmail.com

\begin{abstract}
Renal artery pseudoaneurysm is a very rare complication after blunt trauma injury. We report on a case of a 54-year-old man admitted to our hospital for right flank pain and gross hematuria, 5 days after blunt abdominal trauma. The diagnosis of interlobar renal pseudoaneurysm was established by a computed tomography scan and confirmed by angiography. Successful superselective angioembolization was performed. This radiographic intervention is an effective and minimally invasive technique to stop active bleeding from renal artery pseudoaneurysms, when patients are hemodynamically stable and where technically feasible. A review of the literature was carried out.
\end{abstract}

Keywords: delayed hematuria, blunt renal trauma, minimally invasive technique

\section{Introduction}

Renovascular injuries, such as transection, thrombosis, dissection, and arteriovenous fistula formation are unusual but well-recognized consequences of blunt abdominal trauma. ${ }^{1,2}$ Renal artery pseudoaneurysm (RAP) usually results from iatrogenic renal procedures, although it can also be a rare complication of blunt abdominal trauma. ${ }^{2,3}$

We report on a very rare case of interlobar RAP, presenting 5 days after blunt abdominal trauma, managed with superselective angioembolization. This is a minimally invasive, effective procedure to manage traumatic RAP, for patients who are hemodynamically stable. ${ }^{3,4}$ A successful clinical outcome, with minimal renal parenchyma loss, can be obtained. ${ }^{1-9}$ Advances in microcatheter technology have enabled superselective catheterization and the embolization of distal arteries smaller than $1 \mathrm{~mm}$ in diameter, improving functional outcomes. ${ }^{8,9}$

\section{Case presentation}

A 54-year-old man was admitted to the Emergency Department of the Hospital de São João, Porto, Portugal, a trauma center, for right flank pain and gross hematuria. He was referred from a secondary level health care hospital, where he stayed for 4 days due to a right grade III renal traumatic injury (as per the Organ Injury Scaling Committee of the American Association for Surgery of Trauma) ${ }^{10}$, after falling from a height of 2 meters and sustaining blunt abdominal and right flank trauma. During this period, the patient was hemodynamically stable, without gross hematuria. He underwent conservative management, with bed rest, hydration, antibiotics, analgesics, and serial laboratory and imaging evaluations. 
On arrival at our institution, the patient was hemodynamically stable (blood pressure: 102/71 mmHg, heart rate: $88 \mathrm{bpm}$ ), eupneic, and afebrile, complaining of right flank and abdominal pain. On physical examination, he had right costovertebral angle tenderness, regional ecchymosis, and grossly bloody urine. Blood analysis showed decreased hemoglobin (11.8 g/dL) and hematocrit (33.2\%). He had normal electrolytes and coagulation tests, with a creatinine level of $1.17 \mathrm{mg} / \mathrm{dL}$, corresponding to an estimated glomerular filtration rate (eGFR) of $84.9 \mathrm{~mL} / \mathrm{min} / 1.73 \mathrm{~m}^{2}$, as calculated by the Chronic Kidney Disease Epidemiology Collaboration (CKD-EPI) equation. ${ }^{11}$

A computed tomography (CT) scan showed a $3 \mathrm{~cm}$ posteroinferior laceration of the right kidney, apparently entirely enclosing the thickness of renal parenchyma, clearly without involvement of the renal sinus or excretory system. Moreover, there was a significant delay in elimination of the intravenous contrast, and the right renal pelvic content was spontaneously hyperdense, suggesting hematic nature. During the arterial phase, the inferior third of the right renal parenchyma showed a hyperdense rounded lesion, of $16 \mathrm{~mm}$ at its greatest diameter, suggesting a posttraumatic RAP (Figure 1A). Finally, there was also a posteroinferior right perirenal hematoma, measuring $55 \times 55 \times 37 \mathrm{~mm}$ (Figure 1B). Selective angiography of ventral and dorsal branches of the right renal artery revealed a contusion focus in the upper two-thirds of the right kidney, with partial cortex devascularization. It also showed a RAP, of $16 \mathrm{~mm}$ diameter, from two interlobar branches of the posterior division of the right renal artery (Figure 2A). Superselective embolization of these branches was performed, using a $5 \mathrm{~F}$ catheter, with $2 \times 5 \mathrm{~mm}$ microcoils and gelfoam particles. Postembolization images confirmed the complete pseudoaneurysm devascularization, exclusion of other arterial afferents, and preservation of the remaining renal vasculature (Figure 2B). The patient's postoperative course was uneventful (blood pressure: 132/84 mmHg, heart rate: $81 \mathrm{bpm}$ ). He was discharged 5 days after the procedure, with a normalizing hematocrit (hematocrit 38\%, hemoglobin $12.8 \mathrm{~g} / \mathrm{dL}$ ) and a creatinine level of $1.02 \mathrm{mg} / \mathrm{dL}$, corresponding to an eGFR of $84.9 \mathrm{~mL} / \mathrm{min} / 1.73 \mathrm{~m}^{2}$.

\section{Discussion}

There are few data describing RAP formation after blunt trauma. ${ }^{1-13}$ The first one was reported by Rouppe in 1717 . A sailor fell, striking his flank against the edge of a boat. He presented flank pain and hematuria and died 10 days later. ${ }^{4}$
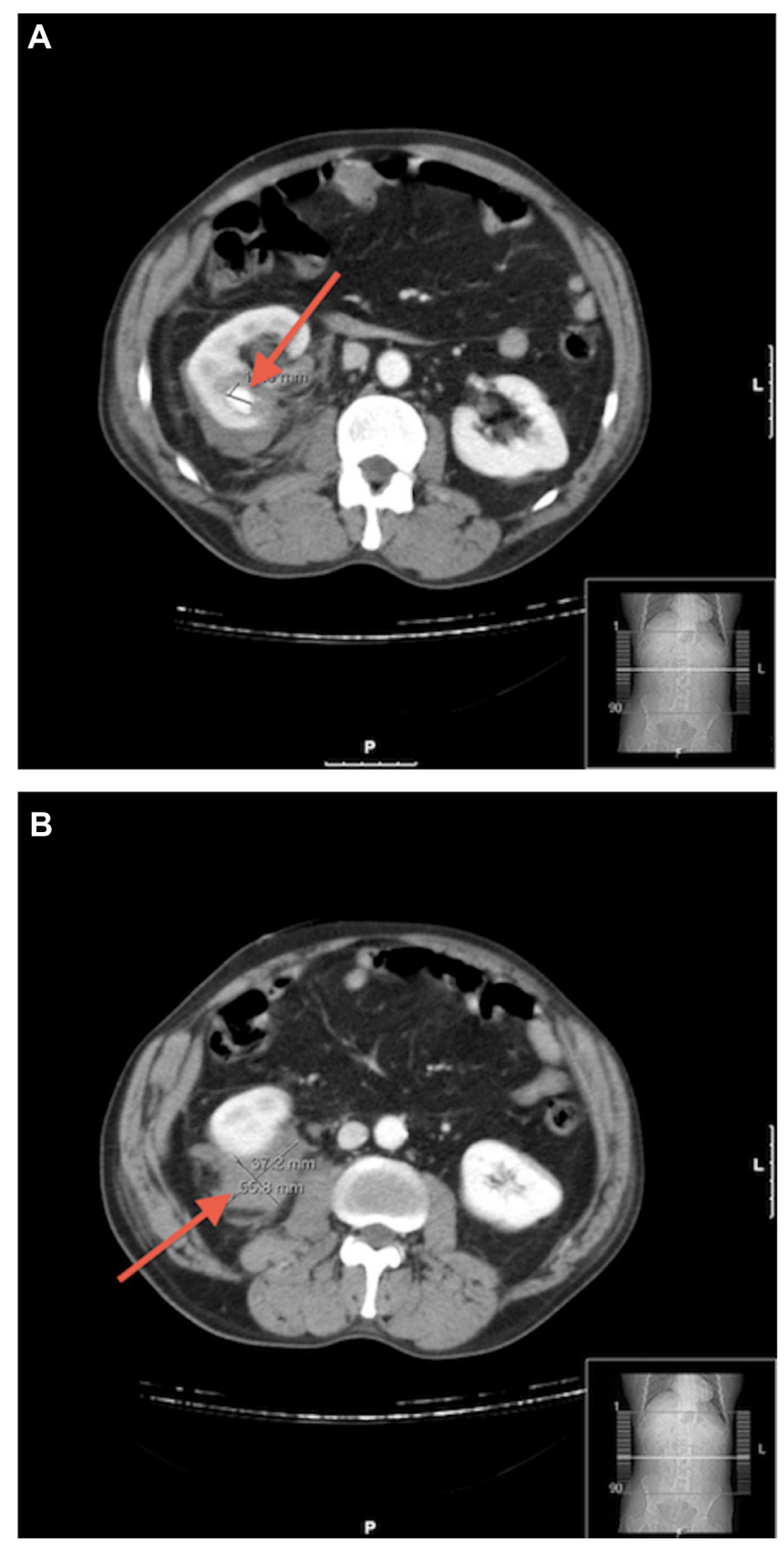

Figure I CT scan findings.

Notes: (A) Contrast-enhanced CT scan shows a hyperdense rounded lesion, of $16 \mathrm{~mm}$ at its greatest diameter (arrow), in the inferior third of the right kidney, compatible with a posttraumatic pseudoaneurysm. (B) CT scan shows a $3 \mathrm{~cm}$ laceration and a perirenal hematoma in the posteroinferior third of the right kidney (arrow).

Abbreviation: CT, computed tomography.

The development of a RAP after blunt abdominal trauma is extremely rare, much less common than following penetrating trauma, and is believed to result from rapid deceleration-induced, full- or partial-thickness injury to arteries supplying the renal parenchyma. ${ }^{1,3,4}$ After complete or partial injury of an artery, the surrounding tissues - vascular adventitia, renal parenchyma, and Gerota's fascia - may contain the hemorrhage. Following the initial renal injury, the combination of hypotension and coagulation results 

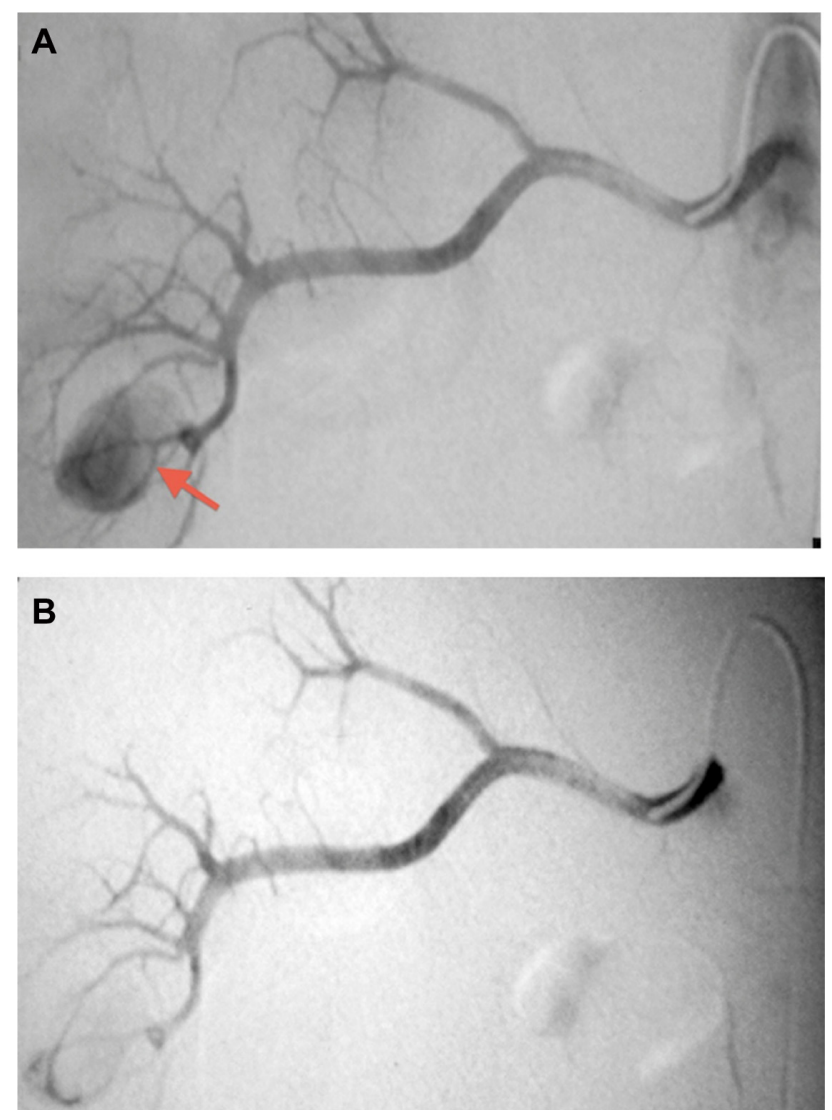

Figure 2 Right renal artery arteriogram findings.

Notes: (A) Ventral and dorsal branches of the right renal artery selective angiogram revealed a mesorenal pseudoaneurysm, of $16 \mathrm{~mm}$ at its greatest diameter (arrow), from two interlobar branches of the posterior division of the right renal artery (B) Superselective embolization of two interlobar branches of the posterior division of the right renal artery was performed, and postembolization images confirmed complete pseudoaneurysm devascularization and preservation of the remaining renal vasculature.

in temporary bleeding cessation. The clot lyses, and surrounding necrotic tissue degradation results in recanalization between the intravascular and extravascular space and, subsequently, the formation of a pseudoaneurysm. With restoration of normal hemodynamics, the pseudoaneurysm can grow and eventually rupture into the pyelocalyceal system or the perirenal space. ${ }^{1,3-5}$ Understanding of this natural history is crucial to the nonoperative management of blunt renal trauma. Typically, gross hematuria from blunt parenchymal injury resolves within several hours and can be effectively managed with bed rest and transfusion support, until the urine clears and vital signs are stable. However, persistent bleeding or delayed gross hematuria should raise the suspicion of segmental vascular injury, including pseudoaneurysm formation, and prompt further investigation. ${ }^{3-5}$ Therefore, although the initial angiogram may be negative, follow-up imaging often demonstrates that with time and resuscitation, previously undetected vascular injuries can blossom into multifocal pseudoaneurysms with active extravasation and gross hematuria.,

Historically, persistent hematuria from blunt renal trauma demanded operative exploration, and nephrectomy was often performed for definitive treatment. Nowadays, advances in radiographic technology and techniques have provided clinicians with minimally invasive alternatives for traumatic renovascular lesion diagnosis and treatment. ${ }^{4,13,14}$ Angiography is the "gold standard" exam used to diagnose traumatic RAP. ${ }^{1,3,4,6,13,14}$ Several noninvasive imaging modalities, ranging from renal ultrasound, intravenous pyelogram, contrast-enhanced CT scan, magnetic resonance imaging (MRI), and renal scintigraphy, can also be used when a pseudoaneurysm is suspected. ${ }^{3,4,6,14}$ Color Doppler ultrasound might be helpful in the evaluation of a renovascular pathologic condition as it can be done in the emergency room or intensive care unit, as a bedside procedure. The pseudoaneurysmal mass is easily detected by the bidirectional swirling blood flow. ${ }^{5,14}$ However, none of these noninvasive exams has been found to be as sensitive as angiography, which not only confirms the presence of a pseudoaneurysm but also, provides anatomic localization and assessment of the renal parenchyma. Moreover, with angiography, concomitant therapeutic embolization is possible., $3,4,5,14$

Treatment of renal parenchymal trauma is generally conservative. Nevertheless, in the particular case of RAP after abdominal trauma, failure to control the bleeding in the acute phase is frequent, even after multiple embolization attempts. ${ }^{4}$ In addition to the hemodynamic status of the patient, the anatomical location of the pseudoaneurysm determines the treatment option-embolization, superselective embolization, stent-graft placement, or open explorative surgery. ${ }^{13,14}$

Regarding blunt trauma, we found few cases successfully treated with embolization. This patient was also effectively managed with superselective embolization, without any medical complications.

Currently, microcatheters are available that allow superselective catheterization and the embolization of interlobular arteries within the renal parenchyma. The evolution of embolization techniques during the past two decades has obviated the need for surgical exploration in many patients with gross hematuria of renal origin after blunt or penetrating abdominal trauma. ${ }^{3,8,9,14}$

As illustrated by this case, transcatheter embolization is safe and effective for controlling hemorrhage from RAP and has become the initial treatment of choice in hemodynamically stable patients. Moreover, this nephronsparing approach may also be effective in reducing late 
complications of blunt trauma, including hypertension and renal failure. ${ }^{3-5,8,9,13}$ Recently, percutaneous stentgraft placement has emerged as an attractive alternative to preserve vessel patency, when the anatomy is suitable, preventing the associated renovascular hypertension. However, there are no published data for the long-term patency of stent-grafts used to treat renal pseudoaneurysms. ${ }^{14}$

\section{Conclusion}

In conclusion, intra-RAP are extremely rare after blunt abdominal trauma. However, when there is persistent bleeding or delayed gross hematuria, this diagnosis should be considered. This can be suggested by CT scan or ultrasound and confirmed by angiography. The management decision, including open exploration (total or partial nephrectomy) or angiographic embolization, is always conditioned by the hemodynamic status of the patient.

\section{Disclosure}

The authors report no conflicts of interest in this work.

\section{References}

1. Swana HS, Cohn SM, Burns GA, Egglin TK. Renal artery pseudoaneurysm after blunt abdominal trauma: case report and literature review. JTrauma. 1996;40(3):459-461.

2. Heyns CF, Stellmacher GA. Selective renal artery embolization in the management of non-iatrogenic renal trauma - experience in 28 patients. African Journal of Urology. 2005;11(2):89-94.
3. Miller DC, Forauer A, Faerber GJ. Successful angioembolization of renal artery pseudoaneurysms after blunt abdominal trauma. Urology. 2002;59(3):444.

4. Jebara VA, El Rassi I, Achouh PE, Chelala D, Tabet G, Karam B. Renal artery pseudoaneurysm after blunt abdominal trauma. J Vasc Surg. 1998;27(2):362-365.

5. Lee DG, Lee SJ. Delayed hemorrhage from a pseudoaneurysm after blunt renal trauma. Int J Urol. 2005;12(10):909-911.

6. Lee RS, Porter JR. Traumatic renal artery pseudoaneurysm: diagnosis and management techniques. J Trauma. 2003;55(5):972-978.

7. Farrell TM, Sutton JE, Burchard KW. Renal artery pseudoaneurysm: a cause of delayed hematuria in blunt trauma. J Trauma. 1996;41(6): 1067-1068.

8. Saad DF, Gow KW, Redd D, Rausbaum G, Wulkan ML. Renal artery pseudoaneurysm secondary to blunt trauma treated with microcoil embolization. J Pediatr Surg. 2005;40(11):e65-e67.

9. More B, Chandran H, Pimpalwar A, John P. A traumatic intra-renal pseudo-aneurysm in a child. Pediatr Surg Int. 2004;20(9):729-730.

10. Santucci RA, McAninch JW, Safir M et al. Validation of the American Association for the Surgery of Trauma organ injury severity scale for the kidney. J Trauma. 2001;50(2):195-200.

11. Levey AS, Stevens LA.Estimating GFR Using the CKD Epidemiology collaboration (CKD- EPI) creatinine equation: more accurate GFR estimates, lower CKD prevalence estimates, and better risk predictions. Am J Kidney Dis. 2010;55(4):622-627.

12. Inoue Y, Ikegawa H, Ukai I, et al. Spontaneous occlusion of splenic and renal pseudoaneurysm after blunt abdominal trauma: a case report and literature review. J Emerg Med. 2010;38(3):e17-e22.

13. Halachmi S, Chait P, Hodapp J, et al. Renal pseudoaneurysm after blunt renal trauma in a pediatric patient: management by angiographic embolization. Urology. 2003;61(1):224.

14. Lindekleiv H, Haro S, Nordhus K, Eggen T, Due J. Renal artery pseudoaneurysm secondary to blunt trauma nine years earlier: case report and review of the literature. Scand J Urol Nephrol. 2008;42(5):488-491.
Research and Reports in Urology

\section{Publish your work in this journal}

Research and Reports in Urology is an international, peer-reviewed, open access journal publishing original research, reports, editorials, reviews and commentaries on all aspects of adult and pediatric urology in the clinic and laboratory including the following topics: Pathology, pathophysiology of urological disease; Investigation and treatment of

\section{Dovepress}

urological disease; Pharmacology of drugs used for the treatment of urological disease. The manuscript management system is completely online and includes a very quick and fair peer-review system, which is all easy to use. Visit http://www.dovepress.com/testimonials.php to read real quotes from published authors. 